\title{
Effect of Injection Timing on Performance and Emissions of DI-diesel Engine Fueled with Isopropanol
}

\author{
Yibin Liu*, Bin Xu, Jianhao Jia, Jian Wu, Weiwei Shang and Zhihao Ma \\ College of Vehicle and Transportation Engineering, Henan University of Science and Technology, Luoyang, China \\ *Corresponding author
}

\begin{abstract}
Experimental study was conducted to investigate the influence of the injection timing on the performance and exhaust emissions of an electronic control high-pressure common rail turbocharged direct injection diesel engine fueled with isopropanol. Diesel fuels with different amounts $(0 \%, 5 \%, 10 \%$, $15 \%$ and $20 \%$ by volume) of isopropanol were used. The results show that the isopropanol addition can significantly improve soot and $\mathrm{CO}$ emissions. Under the same injection timing, with the increase of isopropanol blending ratio, combustion duration shortened, brake specific fuel consumption increased, the peak of in-cylinder pressure and heat release rate of pilot-injection combustion decreased, the peak of in-cylinder pressure and heat release rate of main-injection combustion increased, THC and NOx emissions increased. With the injection timing retarded, the center of heat release rate of pilot and main injection combustion delayed, the peak of in-cylinder pressure and heat release rate of former ascended, the latter descended. Brake specific fuel consumption, CO emission, THC emission and soot emission reduced, NOx emissions increased.
\end{abstract}

Keywords-injection timing; diesel engine; isopropanol; combustion; emissions

\section{INTRODUCTION}

Diesel engines are the most common internal combustion engines that are widely used in various sectors such as agriculture, transportation and industry, due to their excellent drivability and fuel economy. They are expected to become more widespread in the foreseeable future. The increasing concern about the energy demand, depleting oil reserves and the instability of the prices of fossil fuels, together with environmental and health problems related to atmospheric pollution, are impelling the search of alternative cleaner fuels that can alleviate such problems. Alternative fuels in general can be divided them into three categories: Oxygenated fuels such as alcohol, ether, ester (mainly including methanol, ethanol, dimethyl ether, micro algae oil as well as the production of biodiesel from vegetable oil); Synthetic oil, (produced by coal, natural gas or biomass liquid fuel, such as waste plastics oil); Gas fuel (natural gas, liquefied petroleum gas, hydrogen gas, coal gas, methane, etc.) [1-5].

Recently, propanol and butanol isomers are increasing their attractiveness as fuels that may be produced from renewable sources. [6-8]
A few research has been carried out on the isopropanol as an alternative fuel. Lv Xingcai etc. [9] used neat n- heptane, and $10 \% \sim 60 \%$ (by volume) isopropanol $/ \mathrm{n}$ - heptane blend fuels on a single cylinder HCCI engine at $1800 \mathrm{r} / \mathrm{min}$. The experimental results reveal that the ignition timing of low temperature reaction ( LTR) retards, and the peak values of heat release during the LTR decreases with the increase of isopropanol in blend fuels. Holtzapple, M.T. etc. [10] found that through the MixAlco Process converts biomass into mixed alcohol fuels. These salts are separated from the fermentation broth and thermally converted to ketones that are subsequently hydrogenated to alcohols, such as 2-propanol, 2-butanol etc. Myburgh, I.S. [11] investigated a fuel blend containing 20\% so-called 'propanol-plus' and $80 \%$ SASOL diesel was tested in a 4-cylinder direct-injection diesel engine. Performance results with standard injection pump settings indicated that in comparison with operation on pure diesel, operation on the propanol-plus/diesel blend reduced the power by roughly $5 \%$ throughout the speed range.

TABLE I. THE PRINCIPAL PARAMETERS OF DIESEL ENGINE

\begin{tabular}{|c|c|}
\hline Description & Specification \\
\hline Engine model & GW4D20 \\
\hline Cylinder & 4 \\
\hline Bore & $83.1 \mathrm{~mm}$ \\
\hline Stroke & $92 \mathrm{~mm}$ \\
\hline Displacement & $1.996 \mathrm{~L}$ \\
\hline Compression ratio & $16.7: 1$ \\
\hline Rated output \& speed & $110 \mathrm{~kW} \& 4000 \mathrm{r} / \mathrm{min}$ \\
\hline Injection system & Common rail injection system \\
\hline Maximum torque \& speed & $310 \mathrm{~N} \cdot \mathrm{m} \& 1800 \sim 2800 \mathrm{r} / \mathrm{min}$ \\
\hline Maximum injection pressure & $1600 \mathrm{bar}$ \\
\hline
\end{tabular}

At present, the isopropanol application research on the engine is relatively few, and for a diesel engine, fuel injection timing is a major parameter that affects the combustion and exhaust emissions. When the fuel is injected, the state of air changes with the variation in injection timing, and thus ignition delay will vary, so this paper studies the different fuel injection timing on the isopropanol/diesel engine performance and emission characteristics.

\section{TEST FUEL AND LABORATORY EQUIPMENT}

Fuels used in test are conventional 0\# diesel, analysis-level isopropanol. On the basis of diesel oil, configure the volume 
content of $5 \%, 10 \%, 15 \%$ and $20 \%$ mixed fuel respectively. P5, P10, P15 and P20 mean isopropanol/diesel, D100 means pure diesel.

TABLE II. THE MAIN MEASURE EQUIPMENT AND INSTRUMENTS

\begin{tabular}{|c|c|}
\hline Device & Accuracy \\
\hline FC2210Z Intelligent fuel consumption instrument & $0.1 \%$ \\
\hline 2893A Vehicular combustion analyzer & $\pm 0.5 \%$ \\
\hline 2614A Crankshaft signal photoelectric encoder & $\pm 0.002 \%$ \\
\hline GW250 Electric eddy current dynamometer & $\pm 1 \mathrm{r} / \mathrm{min}$ \\
\hline FC2000 Measurement and control system & $\pm 0.2-0.4 \% \mathrm{FS}$ \\
\hline Horiba MEXA-7100DEGR Gas emissions analyzer & $\pm 1 \%$ \\
\hline
\end{tabular}

Experiments for pure diesel and isopropanol/diesel fuel blends were conducted in a 4 cylinder, 4 stroke, water-cooled, turbocharged, common-rail, direct injection diesel engine. Main technical specifications of the engine are given in Table I Fuel injection timing by needle valve opening time (by Kistler cylinder pressure sensors, the combustion analyzer and Kibox Cockpit software) have been measured to determine. The main measure equipment and instruments in Tab. II. The physical and chemical characteristics of pure diesel and blended fuels are presented in Table III.

Since middle speed represent the typical road-load conditions for automotive diesel engines [12], it is expected that the effect injection timing of isopropanol/diesel on performance and emissions will be more significant under these conditions. Therefore, test conditions of 2000 $\mathrm{rpm} / 150 \mathrm{~N} \cdot \mathrm{m}$ and various injection timing $\left(2^{\circ} \mathrm{CA}\right.$ ATDC、 $4^{\circ} \mathrm{CA}$ ATDC、 $6^{\circ} \mathrm{CA}$ ATDC $、 8^{\circ} \mathrm{CA}$ ATDC $10^{\circ} \mathrm{CA}$ ATDC) were selected as the engine operating conditions. The fuel P5, $\mathrm{P} 10, \mathrm{P} 15, \mathrm{P} 20$ and D100 are used in experiment respectively.

TABLE III. PHYSICAL AND CHEMICAL PROPERTIES

\begin{tabular}{|c|c|c|c|c|c|}
\hline Property & D100 & P5 & P10 & P15 & P20 \\
\hline Volume fraction & 0 & 5 & 10 & 15 & 20 \\
\hline $\begin{array}{c}\text { Density }\left(20^{\circ} \mathrm{C}\right) \\
/ \mathrm{g} \cdot \mathrm{ml}^{-1}\end{array}$ & 0.842 & 0.839 & 0.836 & 0.833 & 0.830 \\
\hline $\begin{array}{c}\text { Kinematic } \\
\text { viscosity }\left(20^{\circ} \mathrm{C}\right) \\
/ \mathrm{mm}^{2} \cdot \mathrm{s}^{-1}\end{array}$ & 4.89 & 4.67 & 4.42 & 4.07 & 4.06 \\
\hline $\begin{array}{c}\text { Low heating } \\
\text { value } / \mathrm{MJ}^{-1} \mathrm{~kg}^{-1}\end{array}$ & 45.882 & 44.917 & 44.018 & 43.567 & 43.068 \\
\hline $\begin{array}{c}\text { Surface tension } \\
/ \mathrm{m} \mathrm{N} \cdot \mathrm{m}^{-1}\end{array}$ & 28.55 & 21.71 & 22.93 & 23.45 & 23.67 \\
\hline Flash point ${ }^{\circ} \mathrm{C}$ & 65 & 22 & 20 & 20 & 20 \\
\hline
\end{tabular}

\section{RESULTS AND DISCUSSION}

\section{A. Combustion Characteristics}

Fig. I shows the HRR (heat release rate) and in-cylinder pressure of various fuel blends and various main injection timing. It can be seen that distinctive double peaks of incylinder pressure and HRR are found, the first peak corresponds to the pilot injection, and the second peak reflects the main injection. Characterization of the combustion in cylinder main stages of the second peak is the main object of study [12、13]. With the mixing proportion of isopropanol increase, the first peak of mixed fuel of HRR and in-cylinder pressure decrease and lower than that of pure diesel, the second peak increase and higher than pure diesel. Due to the longer ignition delay of pilot injection raised by isopropanol addition, the mixing process of pilot injected fuel and air is enhanced, which could form over-lean regions where combustion does not happen, results in much lower pilot injection heat release rate and in-cylinder pressure [14]. Main injection phase as a result of the mixed fuel ignition period prolonged, the amount of combustible mixed gas increases, premixed combustion ratio increases, and isopropanol oxygen promote the process of combustion, the peak of HRR and incylinder pressure increases. The interval of the first peak and the second gradually descend with the ratio of isopropanol ascend, this can be attributed to the low viscosity and density of isopropanol, the atomization quality improved, the speed of flame propagation accelerated, the combustion duration shortened, then promote the combustion.

The first peak of HRR and in-cylinder pressure decrease when the second peak increase with the injection timing advanced. This is the expected behavior due to pilot injection timing is before the TDC(top dead center), with the fuel injection timing advanced, compression negative work increases, and the temperature and pressure in cylinder is reduced, participate in the combustion mixture gas decreases; Main injection timing after the TDC, when fuel injection timing advanced, the ignition period delayed, increase in the number of combustible mixed gas formation, premixed combustion increase, in addition, the temperature in cylinder higher, more conducive to mixture combustion, thus the combustion efficiency increased.
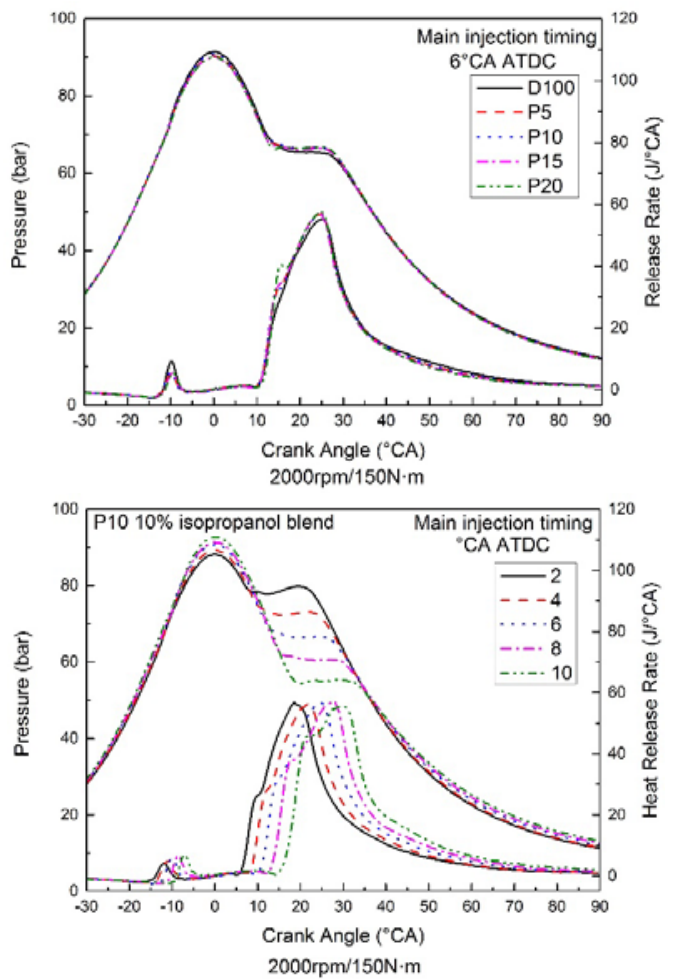

FIGURE I. HEAT RELEASE RATE AND IN-CYLINDER PRESSURE OF VARIOUS BLENDS AND VARIOUS MAIN INJECTION TIMING 


\section{B. Brake Specific Fuel Consumption}

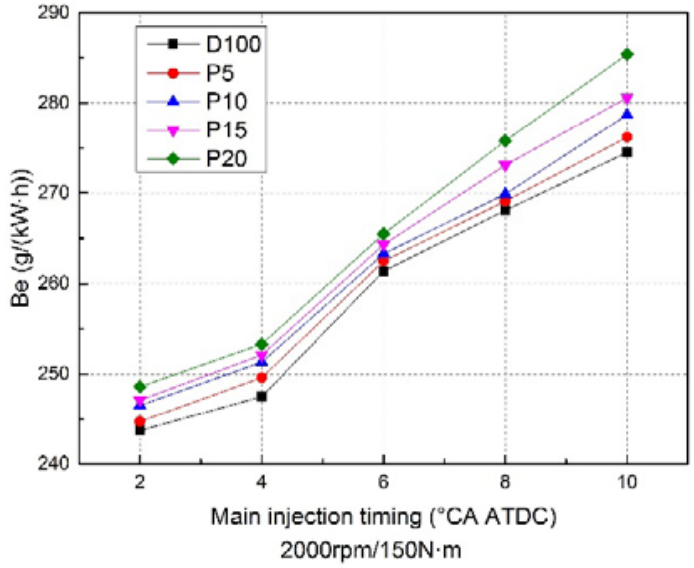

FIGURE II. BSFC OF VARIOUS BLENDS UNDER DIFFIERENT MAIN INJECTION TIMING

Fig. II indicates that the curve of BSFC (brake specific fuel consumption) of various blends under different main injection timing. It can be seen that the BSFC of five kind fuels increases with the increase of the mixing ratio of isopropanol. This is due to the heating value of the fuel blends decreases with the increase of the proportion of isopropanol. In order to get the same output power, cycle fuel injection quantity increases. Thus the BSFC of the mixed fuel is increased. It also can be seen that the BSFC of all fuels decreases with injection timing advanced. In the operating condition of $2000 \mathrm{rpm} / 150 \mathrm{~N} \cdot \mathrm{m}$ the combustion occurs after TDC and in the expansion stroke. At this time, the heat transfer loss decreases and the fuel consumption is reduced. In addition, the fuel injection timing is advanced, the ignition delay period is prolonged, the amount of combustible mixture is increased, and the combustion efficiency is improved.

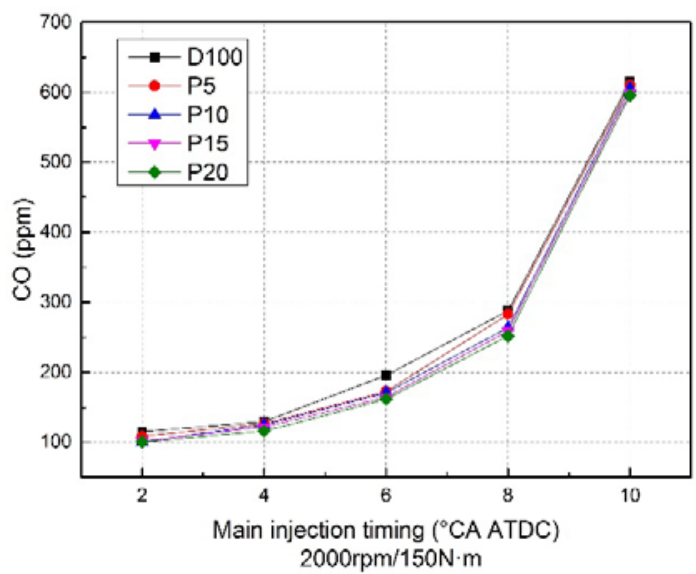

FIGURE III. CO EMISSIONS OF VARIOUS BLENDS UNDER VARIOUS MAIN INJECTION TIMING

\section{Emissions}

\section{1) CO emission}

The figure III shows that the CO emission decreases with the injection timing advanced. Oxidation of $\mathrm{CO}$ to $\mathrm{CO} 2$ conditions are: the presence of oxygen, suitable temperature and a longer period of time. Under the same operating condition, the $\mathrm{CO}$ emission increases with the delay of the fuel injection timing. This is because the combustion occurs after TDC. At this time, the cylinder temperature is lower. With the injection timing delayed, the ignition delay is shortened, the proportion of premixed combustion is reduced, and the $\mathrm{CO}$ from combustion of combustible mixture is not oxidized and frozen [15]. Compared with the pure diesel fuel, the CO emission of the mixed fuels is reduced under the same fuel injection timing. The oxygen content of isopropanol increases the oxygen concentration in the combustion process, and makes the combustion of combustible mixture more complete. As the isopropanol mixing ratio increases, $\mathrm{CO}$ emission reduction ratio decreases. This may be attributed to synergistic effects of the latent heat of vaporization of isopropanol, and the oxygen content of isopropanol.

\section{2) THC emission}

As can be seen from the Fig. IV, the THC emission decreases with the injection timing advanced. The emission of $\mathrm{HC}$ is mainly caused by the unburned fuel and incomplete combustion. Under the same operating condition, the amount of air entering the cylinder is equal. With the fuel injection timing advanced, the ignition delay period is prolonged, the proportion of premixed combustion increases, the pressure and temperature in the cylinder increases, and the oxidation process of hydrocarbon fuels is accelerated. Thus the production of THC decreases with the injection timing advanced. With isopropanol mixing ratio increases, THC emission increases. Generally speaking, the shorter the ignition delay period, the lower the HC emission is [16]. The cetane number of isopropanol is low, the ignition delay period is long, and the more hydrocarbon wall quenching. At the same time, isopropanol containing oxygen, reducing the area of over concentrated mixture in the cylinder, the combustion efficiency improved. And the $\mathrm{HC}$ emission caused by the lack of oxygen in the combustion process of diesel engine is also decreased $[9,16]$.

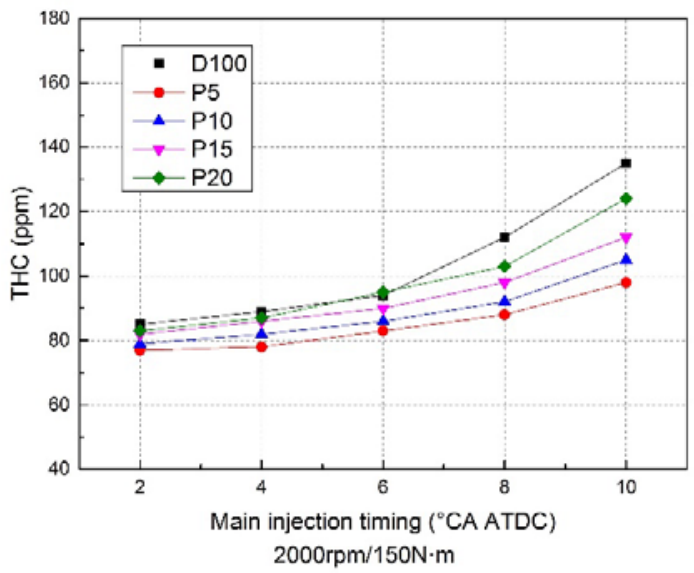

FIGURE IV. THC EMISSIONS OF VARIOUS BLENDS UNDER VARIOUS MAIN INJECTION TIMING 
3) NOx emission

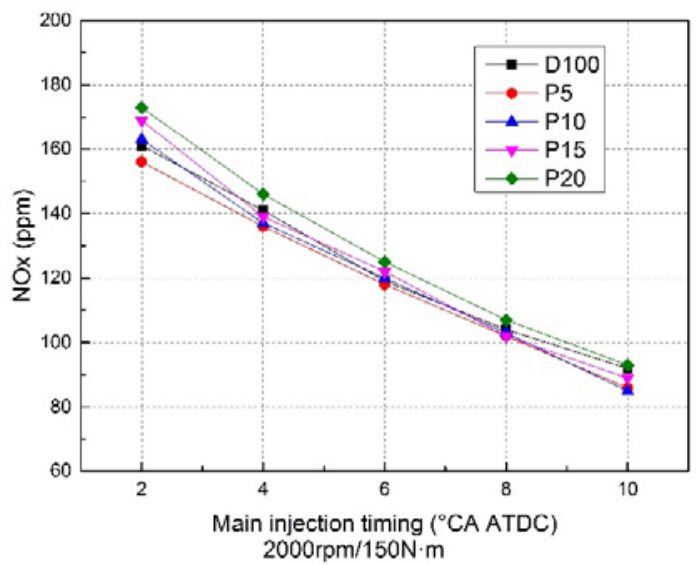

FIGURE V. NOX EMISSIONS OF VARIOUS BLENDS UNDER VARIOUS MAIN INJECTION TIMING

It is well known that the formation conditions of NOx are: high temperature, enough oxygen and sufficient reaction time. We can see that the NOx emission increases sharply with the fuel injection timing advanced by the Fig. $V$. This is in accordance with that the fuel injection timing is advanced, the combustion time is ahead of time, the ignition delay period is prolonged, the proportion of the premixed combustion increases, and the highest temperature and pressure in the cylinder increase. The premixed gas is in the state of oxygen enrichment. With the increase of the proportion of the premixed combustion, the temperature of fast combustion period in the cylinder is increasing rapidly, and the combustion duration increases. This makes the three formation conditions of NOx are enhanced, so the NOx emission increases.

\section{4) Smoke emission}

It is pointed out that the smoke emission increases with the decrease of injection timing advance form Fig. VI. This is because the fuel injection timing is in advance, the ignition delay period is prolonged, the proportion of premixed combustion increases and the peak of heat release rate increases. The pressure and temperature in cylinder is increasing. The combustion of $\mathrm{HC}$ from the fuel pyrolysis is more completely. This reduces the number of polycyclic aromatic hydrocarbons generated by small molecular weight $\mathrm{HC}$, so as to restrain the formation of smoke. Generally speaking, the formation of smoke is mainly caused by the cracking of high polymer hydrocarbon (especially the aromatic hydrocarbon ) in high temperature and lack of oxygen in the concentrated mixture area of the combustion chamber[17]. The components of aromatic and naphthenic hydrocarbons in diesel provide a large number of complete aromatic and aromatic free radicals for the growth of smoke particles. It is helpful to the basic carbon particles in the formation of particles in the process of interaction with each other. Thus the formation of large particles containing more basic carbon particles and branched chain [18]. The content of aromatic hydrocarbon decreases after the diesel is blended with isopropanol. This "dilution effect" inhibits the formation of smoke emissions at the source. In addition, the boiling point and viscosity of isopropanol are lower, and the quality of fuel atomization is improved. The gas and fuel are mixing more fully, and the area of the over concentrated mixture is reduced. The latent heat of vaporization of isopropanol can reduce the combustion temperature of the cylinder, thereby reducing the thermal cracking reaction of fuel, and inhibiting the formation of smoke. Besides, the isopropanol is an oxygenated fuel, which promotes the combustion process, which is conducive to the further oxidation of smoke. Finally, the longer ignition delay period of fuel blends improves the degree of premixing of fuel and air, which is another reason for the decrease of the smoke emission. Therefore, under the same fuel injection timing, the smoke emissions of the mixed fuel were significantly lower than that of the net diesel fuel.

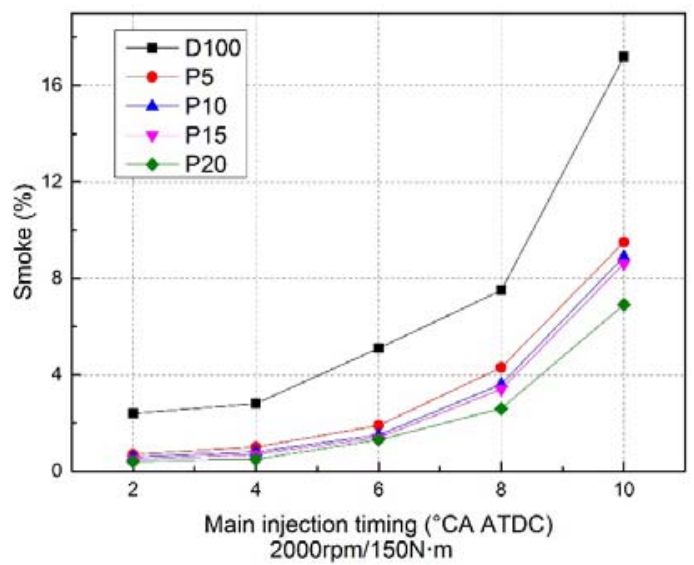

FIGURE VI. SMOKE EMISSIONS OF VARIOUS BLENDS UNDER DIFFIERENT MAIN INJECTION TIMING

\section{CONCLUSIONS}

In this work, isopropanol as additives to diesel were investigated in terms of performance and emission characteristics of a DI diesel engine running on various injection timing. As the mixing proportion of isopropanol increased, the peaks of in-cylinder pressure and HRR of pilot injection were reduced, both peaks of main injection ascended. Brake specific fuel consumption, the THC emissions and NOx emissions increased, $\mathrm{CO}$ emissions and smoke decreased significantly. With the injection timing advanced, the HRR center of pilot injection combustion and main injection combustion antedisplacement, the former HRR peak and incylinder pressure peak reduced which of latter rise. Brake specific fuel consumption, $\mathrm{CO}$ emission, THC emission and smoke decreased except NOx emission. Compared with the pure diesel, the isopropanol/diesel fuel blends could significantly reduce smoke and $\mathrm{CO}$ emissions. Comprehensive consideration of engine combustion, economy and emission performance, recommended optimal mixing proportion of isopropanol is $10 \%$.

\section{ACKNOWLEDGMENT}

The work was supported by International cooperation project of Henan province (144300510039). 


\section{REFERENCES}

[1] Avinash Kumar Agarwal, Atul Dhar, Jai Gopal Gupta, et al. Effect of fuel injection pressure and injection timing of Karanja biodiesel blends on fuel spray, engine performance, emissions and combustion characteristics. Energy Conversion and Management 91 (2015) 302-314

[2] D.C. Rakopoulos, C.D. Rakopoulos, et al. Effects of butanol-diesel fue blends on the performance and emissions of a high-speed DI diesel engine. Energy Conversion and Management 51 (2010) 1989-1997.

[3] John Benjamin Heywood. Internal Combustion Engine Fundamentals [M]. New York: McGraw-Hill Book Company, 1988.

[4] Teresa M. Mata, Adélio M. Mendes, et al. Sustainability and economic evaluation of microalgae grown in brewery wastewater. Bioresource Technology 168 (2014) 151-158

[5] M. Mani, G. Nagarajan. Influence of injection timing on performance, emission and combustion characteristics of a DI diesel engine running on waste plastic oil. Energy 34 (2009) 1617-1623.

[6] Claudia Esarte, María Abián, Ángela Millera, María U. Alzueta. Gas and soot products formed in the pyrolysis of acetylene mixed with methanol, ethanol, isopropanol or n-butanol. Energy 43 (2012) 37-46

[7] Kohse-Höinghaus K, Oßwald P, Cool T, Kasper T, Hansen N, Qi F, et al. Biofuel combustion chemistry: from ethanol to biodiesel. Angew Chem Int Ed 2010;49:3572-97.

[8] Nigam PS, Singh A. Production of liquid biofuels from renewable resources. Progr Energy Combust Sci 2010;37:52-68.

[9] Lv Xingcai, JI Li bin, et al. Parametric Study on Emissions and Heat Release Analysis of Combustion of HCCI Engines Fueled with Isopropanol/n-Heptane Blend Fuels. Journal of Combustion Science and Technology, 2007,13(3).

[10] Hotzapple M, Davidson RR, Ross MK, Aldrett-Lee S, Nagwani M, Lee $\mathrm{M}$, et al.Biomass conversion to mixed alcohol fuels using the MixAlco process. Appl Biochem Biotechnol 1999;79:609-31.

[11] Myburgh IS. Performance and durability testing of a diesel engine fuelled with a propanol-plus/diesel blend. SAE Paper 1986;95:1011-21

[12] Donghui Qi a, $\square$, et al. Effect of EGR and injection timing on combustion and emission characteristics of split injection strategy DIdiesel engine fueled with biodiesel. Fuel 90 (2011) 1884-1891

[13] Mei Deqing, Ren Hua, et al. Effects of multiple injections strategy on combustion process of mixed fuels with dimethyl carbonate and diesel[J]. Transactions of the Chinese Society of Agricultural Engineering (Transactions of the CSAE), 2014, 30(8): 74-80.

[14] Mingfa Yao *, Hu Wang, et al. Experimental study of n-butanol additive and multi-injection on HD diesel engine performance and emissions. Fuel 89 (2010) 2191-2201.

[15] John Benjamin Heywood. Internal Combustion Engine Fundamentals [M]. New York: McGraw-Hill Book Company, 1988.

[16] Ma Zhihao, Wang Xin, et al. Effects of fuel injection timing on economy and emissions of diesel engine fueled with diesel/biodiesel blends[J]. Transactions of the CSAE, 2011, 27(2): 151-155.

[17] Jiang Deming. Advanced Internal Combustion Engine Fundamentals [M]. Xi'an : Xi 'an jiaotong university press, 2007.

[18] Danna A., Ciajolo A., et al. Effect of fuel/air ratio and aromaticity on the molecular weight distribution of soot in premixed n-heptane flames, Proc. Combust. Inst., 2009, 32 (1):803-810 